\title{
The Relationship between Income and Tourism Demand: Old Findings and New Research
}

\author{
Helena Nemec Rudež \\ University of Primorska, Faculty of Tourism Studies - Turistica, Slovenia \\ helena.nemec@fts.upr.si
}

The purpose of this paper is to review the main findings regarding the income/tourism demand relationship and discuss the development of this relationship over time as well as its impact on tourism growth. The paper draws significant findings regarding the income elasticity of tourism demand, highlighting the most recent research on this topic and examines future aspects of the income/tourism demand relationship. A literature review along with UNWTO and IMF reports was studied and assessed to discuss the income elasticity research in recent decades as well as more recent developments in this area. Income elasticity of tourism demand is today lower than in the past due, firstly, to the long-term growth of tourism demand leading to demand saturation and stagnation of some tourism products, and, secondly, fluctuations across the business cycle. The paper summarizes the main findings and contributions of studies on the income elasticity of tourism demand thus far and reflects tourism demand sensitiveness to income as a tourism growth driver.

Keywords: income elasticity, tourism demand, luxury product, necessity

https://doi.org/10.26493/2335-4194.11.67-73

\section{Introduction}

The relationship between income and demand is one of the main concerns in economics. Meta-analyses reveal an extensive body of research on this relationship in tourism demand (Crouch, 1995; Peng, Song, \& Crouch, 2014; Peng, Song, Crouch, \& Witt, 2015), air travel demand (Gallet \& Doucouliagos, 2014), and other areas, such as residential water demand (Dalhuisen, Florax, de Groot, \& Nijkamp, 2003). Regarding tourism, income in origin markets is recognized as a dominant explanatory variable of international tourism demand by many authors (Crouch, 1994; Lim, 1997; Peng et al., 2015).

The study of the relationship between income and recreation demand relationship started in the 19th century, explained with Engel's law. Since then, a number of studies have been undertaken on the relationship between income and tourism demand. Knowing tourism demand, its characteristics and relationship with income is of great importance to researchers and practitioners especially because of the perishability of tourism products. Indeed, Dwyer, Forsyth and Dwyer (2010) highlight that the understanding of tourism demand and its forecasting is essential for tourism marketers, managers, planners and public agencies.

The relationship between income and tourism demand is usually estimated with the income elasticity of tourism demand-based macroeconomic data using time data series as well as panel data. Furthermore, studies on consumer surveys were undertaken lately to assess the relationship between income and tourism spending (Bronner \& Hoog, 2016). Reviews of studies on the income elasticity of tourism demand (Crouch, 1995; Song \& Li, 2008; Peng et al., 2015) show that explanatory and dependent variables, time periods of data, methodologies and origin/destination pairs influence the income elasticity of tourism demand.

Song, Li, Witt, and Fei (2010) found that the most 
used proxies for tourism demand are the number of tourist's arrivals and tourist expenditures, but also the number of tourist's overnight stays and the length of stay have been used. While the number of visitors is difficult to measure undertaking frontier counts for international visitors, the number of tourists' arrivals and overnight stays are easily available based on statistical reports of accommodation facilities. Tourist expenditures are reported as international receipts and international expenditures in country's balance of payment and are usually measured using visitor surveys and, as such, being the subject of data collection problems and leakages (Frechtling, 1987, in Song et al., 2010). With regards to income, it is usually measured in nominal or real GDP or GDP per capita. Song and Witt (2000) highlight that personal disposable income or private consumption is a better proxy for income when leisure tourism is investigated. Other measures of income that were used in the past studies exist, such as industrial production indices (Gonzales \& Moral, 1995, in Peng et al., 2015), foreign travel budgets (Smeral \& Witt, 1996, in Peng et al., 2015). Moreover, tourism demand can also be influenced by past income in the origin market 'since changes in income may take some time to affect tourism demand' (Lim, 1997, p. 842).

The purpose of this paper is to review the main findings about income/tourism demand relationship and discuss the change of this relationship over time as well as its impact on tourism growth. The paper discusses significant findings about the income elasticity of tourism demand, highlighting the most recent research on this topic and examines future aspects of income elasticity.

\section{Income Elasticity of Tourism Demand}

Since the 1960s, there has been an increasing concern in research on the income elasticity of tourism demand (Crouch, 1995; Smeral, 2004; Peng et al., 2014). In fact, the relationship between tourism demand and income has been widely researched in the form of income elasticity, which measures the sensitivity of tourism demand to changes in income. Specifically, it is the ratio of the percentage change in tourism demand to the percentage change in income.
Regarding the elasticity of tourism demand, income elasticity is the most frequent variable assessed, following own-price elasticity, cross-price elasticity (referring to substitute tourism products or products in joint demand), and the elasticity of habit persistence and expectations. ${ }^{1}$ Tourism demand elasticity can be estimated for any influencing factor, which is adequately measured and reported. ${ }^{2}$

In line with the direction and magnitude of income elasticity of tourism demand, tourism products are classified as luxuries (having coefficient positive and higher than 1 and being income elastic) or necessities (having coefficient positive and between o and 1 and being income inelastic). The higher the coefficient is, the more luxurious the tourism product is and, vice versa, the closer to o the coefficient is, the more necessity is perceived in the tourism product. Products with negative elasticity coefficient are perceived as 'inferior.' In the same way, tourism destinations can be classified.

A meta-analysis of tourism demand performed by Crouch (1995) found that about $70 \%$ of estimated income elasticities of international tourism demand were income elastic with coefficients higher than 1, and $5 \%$ of the estimated income elasticities were negative, referring to an 'inferior' destination or possible estimation error. Since income is an essential influencing factor of tourism demand, income-elastic international tourism demand has been an important driver of tourism growth. Higher values of income elasticity were found when tourism demand is measured in terms of tourist arrivals than when it is measured in terms of expenditure (Peng et al., 2015). Moreover, income elasticity of tourism demand depends on how

${ }^{1}$ It is measured by lagged tourism demand variable.

${ }^{2}$ In a study of Italian domestic tourism, Massida and Etzo (2012) calculated elasticities regarding population density, aerial distance between town of origin and destination, income (measured in GDP), price (measured in ratio of CPI at destination to $\mathrm{CPI}$ at region of origin), the ratio of residents travelers in the region of origin who travel abroad, regional endowment of touristic places, regional expenditures in cultural activities, ratio of national museums with entrance fee, highways kilometres, the presence of minor crime over total one, $\mathrm{CO}_{2}$ emissions. 
income is measured, revealing that income elasticity is higher when permanent income is included that when current income is obtained in the study; it is also sensitive to the sample population, specifically whether only those that travel or the whole population is included in the research (Alegre \& Pou, 2016).

The study by Smeral (2004) investigated the income elasticity of outbound tourism demand between 1975 and 1999, finding that international outbound tourism was a luxury good, being income elastic in 24 out of 25 countries. Later studies also show that inbound international tourism is a luxury good, for instance, the study on tourism demand in Spain (GarinMunoz, 2007) and Turkey (Dogru, Sirakaya-Turk, \& Crouch, 2017). In general, international tourism is widely recognized in the literature as being income elastic.

Nevertheless, international tourism can have characteristics of necessities when destinations are close to origin markets. Nemec Rudež (2016) found that Slovenia as a close destination is recognized as a necessity for tourists from Austria and Italy, probably due to time and financial convenience. This is consistent with the findings of Peng et al. (2015) that long-haul travel is considered more luxurious, having higher coefficients of income elasticity than short-haul travel does.

Studies on the income elasticity of tourism demand usually focus on the general tourism demand. From the viewpoint of tourism suppliers, it is more appropriate to look at the income elasticity of specific tourism products. Divisekera (2010) focused on specific products consumed by tourists while visiting Australia from different foreign origin markets and found that the coefficient of income elasticity of inbound tourism demand varies across tourism products. Specifically, accommodation is recognized as a luxury and shopping as a necessity, whereas other tourism products are income inelastic or income elastic depending on that origin market. Investigations of the income elasticity of specific tourism products aid in better understanding the insights of tourism demand.

\section{Changes in Income/Tourism Demand Relationship}

The relationship between household demand and household income was first described in 1857 by Ernst En- gel, who stated that as household income increases, the percentage of income spent on recreation and similar products increases more than proportionally. This happens when basic needs (like food) are satisfied. In terms of income elasticity, it means that recreation is income elastic and characterized as a luxury good. However, a higher standard of living throughout the 2oth century led to a decrease in the income elasticity of tourism demand. Costa (1997) estimated the income elasticities of several recreational goods and found that they had fallen during the period of more than 100 years between 1888 and 1991 from 4 to slightly above 1 . A downward trend of income elasticity of tourism demand is present because the long-term increase in real income increases the level of satisfaction with tourism products and, consequently, makes tourism demand less income sensitive. In other words, income elasticity gives an insight into the future growth of tourism demand. The lower the income elasticity of tourism products is, the nearer the tourism market to is the saturation level.

International tourism remains widely recognized as a luxury good in many studies. In line with this, tourism demand has been facing high growth rates worldwide. However, if we look closely at the tourism growth rate, it has been decreasing in the past decades following a weaker sensitivity of tourism demand to changes in income. As reported by UNWTO statistics (UNWTO, 2005, 2011), there was a 10.6\% average annual growth rate in international tourist arrivals worldwide between 1950 and 1960, followed by a 9.1\% average annual growth rate between 1960 and 1970 and a 5.3\% average annual growth rate between 1970 and 1980 , a $4.7 \%$ average annual growth rate between 1980 and 1990 , and it fell to only $4.4 \%$ between 1990 and 2000 ; it was followed by a $3.4 \%$ average annual growth rate between 2000 and 2010. Additionally, looking at only advanced economies, the annual growth rate was even lower (UNW TO, 2011).

Recent studies show that the income elasticity of tourism demand further fell during the economic crisis of the past decade. Gunter and Smeral (2016) compared the income elasticity of tourism demand in different world regions, finding that during the period between 2004 and 2013 it was lower than pre- 
viously because of the great recession between 2007 and 2009, financial crises, increasing unemployment, and insecurity; in fact, during the decade between 2004 and 2013, tourism goods became income inelastic with the coefficient varying from 0.20 in Southern Europe to 0.99 in Asia, reflecting the fact that tourism has become a necessity. Additionally, Gunter and Smeral (2017) investigated income elasticity across the business cycle, dividing it into fast growth-periods (expansion, peak and slowdown) and slow growthperiods (recession, through and recovery), revealing that between 2004 and 2014 tourism products were income elastic during slow growth periods (luxurious) and income inelastic (necessities) during fast growthperiods. The reasons for the changing income elasticity of the tourism demand across the business cycle are loss aversion, liquidity constraints, and precautionary savings (Smeral, 2016). During a crisis, consumers pay more attention to spending and, thus, increase precautionary savings because of higher uncertainty about the future.

Consumers undertake different economizing strategies during the recession, which enable them to participate in actual tourism demand, such as reduced length of stay, cheaper accommodation, closer to home, fewer holidays, changed period of travel and cheaper transport (Campos Soria, Inchausti-Sintes, \& Eugenio-Martin, 2015). Travelling closer home reflects the substitution of the international travel with domestic travel. However, tourists' economizing decisions on tourism expenditure differ across climate conditions of the origin country (Eugenio-Martin \& CamposSoria, 2014), education, occupation and age (CamposSoria et al., 2015). Because of spending pattern changes during different phases of the business cycle, promotional strategies cannot remain unaffected by this phenomenon. Lee, Taylor, and Chung (2011) highlighted that the economic crisis has lead to the use of more rational and functional features in promotional strategies. The goal of promotional strategies should be, of course, to turn the income/tourism demand relationship to the favour of tourism suppliers and destinations.

The most recent economic crisis also revealed how the income/tourism demand relationship differs between different tourism products. Based on a ques- tionnaire on holiday patterns, Brooner and Hoog (2017) found that the main summer holidays have an asymmetric tourism demand, belonging to the category of necessities during crisis because of crisisresistance and to the category of luxuries exhibiting considerable growth during the expansion phase of the business cycle; in contrast, short in-between vacations and day trips are 'classic luxuries,' with symmetric tourism demand across the business cycle with substantial demand decrease during recession and considerable growth during the recovery. Regarding economizing priorities during crisis, the main summer holiday exhibits a low economizing priority, which suggests that consumers economize on other products.

In summary, the income elasticity of tourism demand is continuously changing due to, firstly, longterm increases in the standard of living and, consequently, increasing levels of satisfaction with the tourism products consumed, and, secondly, fluctuation across the business cycle.

\section{Future Tourism Growth and Income/Tourism Demand Relationship}

Gunter and Smeral's recent study (2017) on the income elasticity of tourism demand poses a question of whether the income elasticity of tourism demand could become elastic after the economic crisis in the near future, highlighting that this largely depends on economic and political frameworks. Moreover, both income elasticity growth and tourism demand growth will probably differ based on the tourism product type. Higher income elasticity will be probably related to the experience-oriented tourism products with highgrowth perspectives, while lower income elasticity will be present for products with low-growth perspectives or stagnation, such as mass-tourism products, according to Gunter and Smeral (2016).

Indeed, tourism demand and its growth depend on income and its elasticity as discussed by Gunter and Smeral (2016). Income growth measured by the real GDP annual growth rate in advanced economies is today lower than in the past (Figure 1). According to the IMF's economic forecasts (see https://www.imf.org), the real GDP annual growth rate will be around $2 \%$ in advanced economies in the coming years. Along with the low-income elasticity of tourism demand, 


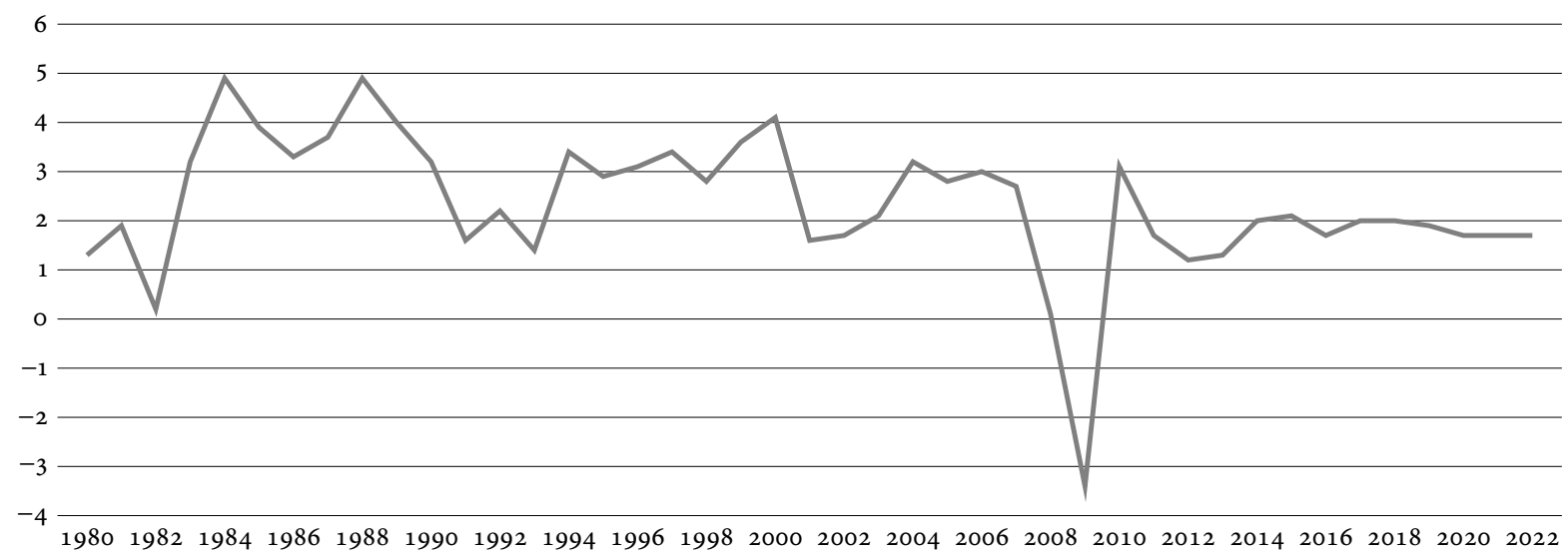

Figure 1 Real GDP Annual Growth (\%) of Advanced Economies in the Period between 1980 and 2016 and Forecasts for the Period 2017-2022 (based on data from International Monetary Fund, www.imf.org)

it reveals that tourism growth, especially in terms of tourism spending, will probably remain low. As mentioned above, experience-oriented tourism products will probably have high tourism growth.

Tourism today faces the high growth of tourists' arrivals; however, from the economic standpoint, knowing the growth of expenditures is essential. Peng et al. (2015) found that income elasticity has lower values when measured in terms of expenditures than when measured in terms of tourist arrivals. Tourism growth during 2004 and 2013 was merely due to physical tourism demand (tourist arrivals and overnight stays) and not expenditures (Gunter and Smeral, 2016). It can be concluded that tourism expenditures will not be as high as they were in the past nor will they be in terms of physical measures of tourism demand. Following forecasts of tourists' arrivals for the 2020-2030 period (UNWTO, 2017), average annual growth rate of tourists' arrivals in advanced economies will be $1.8 \%$, which is lower than in the past (2.6\% forecasted for the period between 2010 and 2020 and $2.7 \%$ in the period between 1995 and 2010). Thus, tourism growth rate is diminishing in terms of tourists' arrivals, and probably it will be even lower in terms of expenditures.

\section{Conclusion}

The income elasticity of tourism demand has attracted much interest in the tourism literature. Understanding how consumers respond to income changes provides a useful tool for tourism planning and gives crit- ical insights into tourism demand to decision makers for strategy and policy implementation. The paper discusses the relationship between income and consumption in the field of tourism.

In general, tourism demand is currently growing more slowly than income and GDP than in the past. Consumers are less sensitive to income than in the past because of the rising purchasing power, but income elasticity of tourism demand varies cyclically across the business cycle. Moreover, the tourism industry in different countries is confronted with consumers with different income elasticities that require marketing strategies adapted to each specific origin market. Tourism products and destinations facing with lowincome elasticity can foster demand growth by targeting new segments with a high-income elasticity of tourism demand or/and design experience-based innovative products with high growth potential, such as products oriented towards customer's new experiences, local knowledge and heritage issues.

As the final word, savings and savings regimes also have a significant impact on tourism consumption as noted by Wang (2014). Further research on the relationship between savings and income elasticity of tourism demand, especially among different income groups, would be welcome.

\section{References}

Alegre J., \& Pou, L. (2016). Us household tourism expenditure and the Great Recession: An analysis with the Con- 
sumer Expenditure Survey. Tourism Economics, 22(3), 608-620.

Brooner, F., \& de Hoog, R. (2017). Tourist demand reactions: Symmetric or asymmetric across the business cycle? Journal of Travel Research, 56(7), 839-853.

Campos Soria, J. A., Inchausti-Sintes, F., \& Eugenio-Martin, J. J. (2015). Understanding tourists' strategies during the global economic crisis. Tourism Management, 48, 164173 .

Costa, D. L. (1997). Less of a luxury: The rise of recreation since 1888 (NB E R Working Paper No. 6054). Cambridge, MA: National Bureau of Economic Research.

Crouch, G. I. (1994). The study of international tourism demand: A review of findings. Journal of Travel Research, 33(1), 12-23.

Crouch, G. I. (1995). A meta-analysis of tourism demand. Annals of Tourism Research, 22(1), 103-118.

Dalhuisen, J. M., Florax, R. J., de Groot, H. L., \& Nijkamp, P. (2003). Price and income elasticities of residential water demand: A meta-analysis. Land Economics, 79(2), 292308.

Divisekera, S. (2010). Economics of tourist's consumption behavior: Some evidence from Australia. Tourism Management, 31(5), 629-636.

Dogru, T., Sirakaya-Turk, E., \& Crouch, G. I. (2017). Remodeling international tourism demand: Old theory and new evidence. Tourism Management, 6o, 47-55.

Dwyer, L., Forsyth, P., \& Dwyer, W. (2010). Tourism economics and policy. Bristol, England: Channel View Publications.

Engel, E. (1857). Die Produktions und Konsumptionsverhältnisse des Konigreichs Sachsen. Zeitschrift des Statistischen Bureaus des Königlich Sächsischen Ministerium des Inneren, 3, 8-9.

Eugenio-Martin, J. J., \& Campos-Soria, J. A. (2014). Economic crisis and tourism expenditure cutback decision. Annals of Tourism Research, 44, 53-73.

Frechtling, D. (1987). Assessing the impact of travel and tourism: Measuring economic benefits. In J. B. Ritchie \& C. R. Goeldner (Eds.), Travel, tourism and hospitality research handbook (pp. 325-331). New York, NY: Wiley.

Gallet, C. A., \& Doucouliagos, H. (2014). The income elasticity of air travel: A meta-analysis. Annals of Tourism Research, 49, 141-155.

Garin-Munoz, T. (2007). German demand for tourism in Spain. Tourism Management, 28(1), 12-22.

Gonzalez, P., \& Moral, P. (1995). An analysis of the international tourism demand in Spain. International Journal of Forecasting, 11(2), 233-251.
Gunter, U., \& Smeral, E. (2016). The decline of tourism elasticities in a global context. Tourism Economics, 22(3), 466-483.

Gunter, U., \& Smeral, E. (2017). European outbound tourism in times of economic stagnation. International Journal of Tourism Research, 19(3), 269-277.

Lee, T., Taylor, R. E., \& Chung. W. (2011). Changes in advertising strategies during an economic crisis: An application of taylor's six-segment message strategy wheel. Journal of Applied Communication Research, 39(1), 75-91.

Lim, C. (1997). Review of international demand models. Annals of Tourism Research, 24(4), 835-849.

Massida, C., \& Etzo, I. (2012). The determinants of Italian domestic tourism: A panel data analysis. Tourism Management, 33(3), 603-610.

Nemec Rudež, H. (2016). Analiza turističnega povpraševanja izbranih izvornih trgov Slovenije. Koper: Založba Univerze na Primorskem.

Peng, B., Song, H., \& Crouch, G. I. (2014). A meta-analysis of international demand forecasting and implications for practice. Tourism Management, 45(1), 181-193.

Peng, B., Song, H., Crouch, G. I., \& Witt, S. F. (2015). A meta-analysis of international tourism demand elasticities. Journal of Travel Research, 54(5), 611-633.

Smeral, E. (2004). Long-term forecasts for international tourism. Tourism Economics, 10(2), 145-166.

Smeral, E. (2016). Tourism forecasting performance considering the instability of demand elasticities. Journal of Travel Research, 56(7), 913-926.

Song, H., \& Li, G. (2008). Tourism demand modelling and forecasting: A review of recent research. Tourism Management, 29(2), 203-220.

Smeral, E., \& Witt, S. F. (1996). Econometric forecasts of tourism demand to 2005. Annals of Tourism Research, 23(4), 891-907.

Song, H., \& Witt, G. (200o). Tourism demand modelling and forecasting. Amsterdam, The Netherlands: Pergamon.

Song, H., Li, G., Witt, S. F., \& Fei, B. (2010). Tourism demand modelling and forecasting: How should demand be measured? Tourism Economics, 16(1), 63-81.

unw to (2005). Tourism market trends. Madrid, Spain: Author.

Unw to (2011). Tourism highlights. Madrid, Spain: Author. UNw to (2017). Tourism Highlights. Madrid, Spain: Author. Wang, Y. S. (2014). Effects of budgetary constraints on international tourism expenditures. Tourism Management, 41, 9-18.

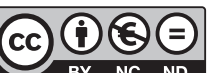

This paper is published under the terms of the Attribution- NonCommercial-NoDerivatives 4.0 International (CC B Y-NC-ND 4.0) License. 


\title{
Student Involvement as a Tool for Nurturing Business Model Development in Tourism Businesses in the Stockholm Archipelago
}

\author{
Gustaf Onn \\ Södertörn University, Department of Environmental Science and Tourism Studies, \\ Sweden \\ gustaf.onn@sh.se
}

Tourism consumption in Sweden is booming, but it seems to be at a standstill in the Stockholm archipelago, and most businesses of all kinds in it are small. Therefore, an EU-Interreg-financed educational community engagement project aiming at business model development in the archipelagos of Turku, Åland (both in Finland), and Stockholm was launched, as Finland has a similar situation. In this paper, the foundations of the project, the literature on the issues of being rural and in the archipelago, and business models are reviewed and put in perspective through preliminary empirical results of the project, in while municipality and some business representatives have been interviewed. The rationale is that there is a weak scientific understanding of business models in use in the archipelagos. Methodologically, action research is being used in addition to document studies, with unstructured interviews and observations as the primary empirical methods. The primary results for which the empirical findings put light on the intersection of the above mentioned literature bodies are the impact of infrastructural and access problems due to isolation, as well as indications of a community split between second homes and permanent residents. The lifestyle-entrepreneurship jeopardises the economic well-being but enriches the social well-being of the population. The primary conclusions are that seasonality and second homers provide entrepreneurs with large output markets in season, but small ones in the off-season. The business equation cannot omit place since it is part of the social well-being of the lifestyle-entrepreneurs, which calls for further research into configurational approaches to strategy in an archipelago context.

Keywords: archipelago business, second homes, lifestyle entrepreneurship, business model development, educational community engagement

https://doi.org/10.26493/2335-4194.11.73-86

\section{Introduction}

The previous decade of tourism development in Sweden was astonishing in economic terms, especially because it essentially bypassed the 2008 financial crisis. At the same time, it seems that that the situation in the Stockholm archipelago has been at a standstill, as will be discussed in the next section. This is despite it being a potent tourist resource, which is being used to market Stockholm. The situation seems to be similar in the archipelagos of Turku and Åland in Finland.

To understand and alleviate this situation, a threeyear EU Interreg-project was initiated on October 1st, 